UDC:616.74-009.17:591.147.3-006.6]-089:612.014.42

DOI: 10.26697/ijes.2019.2.46

\section{Electrophysiological Efficiency of Surgical Treatment of Patients with Generalized Myasthenia Gravis}

Assistant Professor Minukhin D. V. ${ }^{1}$, Professor Klimova E. M. ${ }^{2}$, Professor Yevtushenko D. O.

${ }^{1}$ Kharkiv National Medical University, Ukraine

${ }^{2}$ V. T. Zaycev Institute of General and Urgent Surgery of NAMS of Ukraine, Ukraine

\begin{abstract}
Background:

Myasthenia gravis (MG) is an autoimmune disease, the basis of the pathogenesis of which is the autoimmune process directed against the nicotine acetylcholine receptor of the postsynaptic membrane of the muscle. The pathogenetic mechanisms of the MG development are closely related to thymus. Thymectomy (thymomectomy) allows to achieve a high percentage of remissions $(60-80 \%)$. The use of electrophysiological research methods is an important element in the evaluation of the efficiency of treatment of different clinical forms of MG, including surgical treatment. The aim of the study was to estimate the efficiency of surgical treatment of patients with generalized MG using the analysis of the functional state of neuromuscular synapse in the early and last postoperative period.
\end{abstract}

\section{Methods:}

The study was carried out in the myasthenic center established in 2007 on the basis of the thoracoabdominal surgery department of the GI "Zaycev V. T. Institute of General and Emergency surgery of the National Academy of Medical Sciences of Ukraine" and the GI "Institute of Neurology, Psychiatry and Narcology of the National Academy of Medical Sciences of Ukraine". The study group consisted of 342 patients with a generalized MG. Thymectomy (thymomectomy) was done to 263 patients. To study the effect of surgical treatment on the basic parameters of the functional state of neuromuscular junction, we used the values of "Delta".

\section{Results:}

Analyzing the average values of changes of the main neuromuscular transmission parameters after thymectomy, thymomectomy in "Delta", the following features were identified: thymectomy, thymomectomy had an immediate fast effect on muscle force, leading to its increase by an average of 2 points, already in the first days after the operation; the rapid increase in muscle force corresponds to the effect of reversibility of neuromuscular transmission disorders, manifested by a significant increase in the amplitude of the $\mathrm{M}$ response (144.4-166.4\%) and the expressed decrease in the decrement (by 22-27\%). Thus, as a result of thymectomy, thymomectomy, a very rapid change in the functional state of the synapse occurs with the restoration of all the affected neuromuscular links. Nevertheless, the described immediate effect of thymectomy, thymomectomy did not remain in all patients further.
In comparison, in the late postoperative period (within 12 months after surgery), the maximum effectiveness of surgery (complete remission, with no manifestations of MG; a condition that does not require the use of immunosuppressive therapy, even in maintenance doses) depend on the type of synapses pathology. In patients with Type I of MG maximum efficiency of thymectomy, thymomectomy was noted in $64.8 \%$ of cases, with Type II - in $23.5 \%$ and with Type III - only in $15.0 \%$. Accordingly, the lack of effectiveness (a slight improvement in the state or lack of effect that does not allow to reduce the dose of anticholinesterase and glucocorticoid drugs by more than $50.0 \%$ ) or negative effectiveness of thymectomy, thymomectomy was detected in $25.7 \%$ of patients with Type I, $70.7 \%-$ with second and $80.0 \%$ - with third types of synapse pathology.

\section{Conclusions:}

Evaluation of the results of the electrophysiological study of patients with a generalized MG suggests that there is an immediate efficiency of thymectomy, thymomectomy, which in most patients manifests an explicit improvement in the state and does not depend on the type of synapses pathology. In studying the long-term efficiency of thymectomy, thymomectomy, we found a clear dependence between the type of MG and the results of surgical treatment. Thus, the objective evaluation of the efficiency of thymectomy, thymomectomy should not be carried out earlier than 12 months from the operation. At the same time, it should be noted that the results of such an evaluation may be significantly different from the initial (in the early postoperative period).

\section{Information about the authors: \\ Minukhin Dmitriy Valeriyovych - Doctor of Philosophy in Medicine, Assistant Professor of Department of Surgery No. 1, Kharkiv National Medical University, Kharkiv, Ukraine. \\ Research interests: the study of immunological mechanisms of the corresponding reaction of the organism to stress influences in ontogenesis; https://orcid.org/0000-0003-3371-1178.}

Klimova Elena Mihaylivna - Doctor of Biological Sciences, Professor, Head of Diagnostic Laboratory with Immunoenzym and Immunofluorescence Analysis, V. T. Zaitsev Institute of General and Urgent Surgery of NAMS of Ukraine, Kharkiv, Ukraine.

Research interests: the study of immunological mechanisms of the corresponding reaction of the organism to stress influences in ontogenesis; https://orcid.org/0000-0002-4007-6806.

Yevtushenko Denys Oleksandrovych - Doctor of Medical Sciences, Professor of Department of Surgery No. 1, Kharkiv National Medical University, Ukraine. Research interests: surgery, education, medical science; https://orcid.org/0000-0003-1941-7183.

\section{Corresponding Author:}

Yevtushenko Denys Oleksandrovych

Corresponding Author's Email:

dr.yevtushenko@ukr.net 